Original Article (short paper)

\title{
Differences between genders in anaerobic capacity during a supramaximal effort
}

\author{
Rodrigo A. B. de Poli1,2®, Joel A.M Gonzalez ${ }^{1,2}$, Natalia Fonsati²®, Alessandro M. Zagatto ${ }^{1,2}(0$ \\ ${ }^{1}$ Universidade Estadual Paulista, Laboratório de Fisiologia e Desempenho Esportivo, Bauru, SP, Brasil; ${ }^{2}$ Universidade \\ Estadual Paulista, Programa de Pós-Graduação em Ciências do Movimento, Faculdade de Ciências, Bauru, SP, Brasil
}

\begin{abstract}
Aim: The present study aimed to verify if there is a difference between genders in anaerobic capacity estimated by energetic equivalents of glycolytic and phosphagen pathways ( $\left.\mathrm{AC}_{[\mathrm{La}]+\mathrm{EPOCfast}}\right)$. Methods: In this way, 8 men and 8 women (physical education students) were subjected to the following sequence of tests: session 1) graded exercise test to measure the maximal oxygen consumption $\left(\mathrm{VO}_{2 \max }\right)$ and intensity associated with $\mathrm{VO}_{2 \max }\left(\mathrm{iVO}_{2 \max }\right)$; sessions 2 to 3) familiarization with supramaximal effort at $115 \%$ of $\mathrm{iVO}_{2 \max }$; session 4) supramaximal effort at $115 \%$ of $\mathrm{iVO}_{2 \max }$ to measure $\mathrm{AC}_{[\mathrm{La}]+\mathrm{EPOCfast}}$ Results: The $\mathrm{AC}_{[\mathrm{La}]+\mathrm{EPOCfast}}$ was lower in women compared to men when expressed in absolute and relative values $(-38.11 \% ; p=0.01$ and $-25.71 \% ; p=0.03$, respectively). A non-significant difference was observed in performance in the supramaximal effort $(-12.08 \% ; p=0.15)$, besides which, a likely negative inference was observed when comparing women to men. In addition, energetic equivalents of the glycolytic pathway (e[La- $]$ ) were also lower in women when expressed in relative and absolute values $(-47.01 \% ; p=0.001$ and $-36.71 \% ; p=0.001$, respectively), however no statistical difference was found for energetic equivalents of the phosphagen pathway (ePCr) $(p>0.05)$. Conclusion: The $\mathrm{AC}_{[\mathrm{La}]+\mathrm{EPOCfast}}$ is lower in women compared to men, mainly due to differences in the glycolytic pathway.
\end{abstract}

Keywords: anaerobic capacity, blood lactate concentration, excess post-exercise oxygen consumption, gender.

\section{Introduction}

Performance during short-term high-intensity exercise seems to be different between genders, with a greater performance for males ${ }^{1}$. This difference can be mainly attributed to anthropometric parameters (e.g., body size and muscle fiber composition), physiological responses, such as total muscle temperature ${ }^{2}$, enzymatic activity (e.g., phosphofructokinase and lactate dehydrogenase $)^{3}$, biochemical processes (e.g., purine nucleotide cycle $^{4}$, and catecholamine release ${ }^{5}$.

These physiological differences between genders may directly influence energy supply by non-mitochondrial pathways such as anaerobic capacity (i.e., amount of energy that comes from phosphagen and glycolytic pathways), as phosphofructokinase, lactate dehydrogenase activity, and catecholamine release such as epinephrine has an important role in the glycolytic pathway ${ }^{3,5}$.

Studies have reported differences between genders in anaerobic capacity measured by the maximal accumulated oxygen deficit (MAOD) (e.g., higher MAOD values for men) $)^{6-9}$, even when expressed in absolute and relative values (i.e., relativized for body mass, active muscle mass, and lean mass) ${ }^{9}$. Despite the differences reported, the percentage difference between genders with the same training level in these studies presented large oscillation, between $\sim 23 \%$ and $\sim 32 \%$. This high variation in anaerobic capacity can be attributed to the low reliability of the MAOD method ${ }^{10}$, and to some methodological differences, such as the number of submaximal efforts and intensity of the supramaximal effort (effort above intensity associated with maximal oxygen consumption) ${ }^{11}$.

Some studies ${ }^{12-14}$ have proposed a new method to estimate anaerobic capacity through the energetic equivalents of glycolytic $\left(\mathrm{e}\left[\mathrm{La}^{-}\right]\right)$and phosphagen $(\mathrm{ePCr})$ pathways, obtained by the oxygen equivalent of the net of blood lactate and the fast component of excess post-exercise oxygen consumption (EPOCfast), respectively. Thus, the sum of e[ $\left.\mathrm{La}^{-}\right]$and ePCr is assumed as anaerobic capacity ( $\left.\mathrm{AC}_{\left[\mathrm{La}^{-}\right]+\mathrm{EPOCfast}}\right)$. This method presents some advantages when compared to MAOD, since $\mathrm{AC}\left[\mathrm{La}^{-}\right]+\mathrm{EPOCfast}$ can estimate the $\mathrm{e}\left[\mathrm{La}^{-}\right]$and ePCr separately, is more time-efficient, and presents good reliability ${ }^{13,14}$.

Assuming that $\mathrm{AC}_{\left[\mathrm{La}^{-}\right]+\mathrm{EPOC} \text { ast }}$ seems to be a better and more reliable alternative to measuring anaerobic capacity compared to MAOD, the present study aims to investigate the differences between genders with the same training level in anaerobic capacity estimated by the $\mathrm{AC}_{\left[\mathrm{La}^{-}\right]+\mathrm{EPOCfast}}$, as well as in the equivalent of oxygen from glycolytic and phosphate pathways during a supramaximal running effort.

\section{Material and Methods}

\section{Participants}

A minimum sample size of eight participants (i.e., four men and four women), was calculated for a statistical power of $95 \%$ 
and an alpha value of 0.05 . The sample size was calculated based on the anaerobic capacity gender comparison findings of Weber and Schneider ${ }^{9}$, assuming an effect size of 3.23. Thus, sixteen physical education students, recreationally active, participated in the study, 8 women (age: $22.13 \pm 2.64$ years; weight: $58.68 \pm 6.68 \mathrm{~kg}$; height: $163.75 \pm 7.70 \mathrm{~cm}$ ) and $8 \mathrm{men}$ (age: $22.13 \pm 3.23$ years; weight: $71.87 \pm 11.79 \mathrm{~kg}$; height: $173.63 \pm 4.81 \mathrm{~cm})$.

The participants were instructed to avoid any substance aid that could affect the performance and physiological responses (i.e., alcohol, caffeine, and sodium bicarbonate, among others) and not to perform strenuous exercise $24 \mathrm{~h}$ before each exercise session. Furthermore, the participants reported not having taken ergogenic substances like chronic creatine or beta-alanine in the previous three months.

All participants signed an informed consent detailing all experimental procedures before beginning the study. The present study followed the declaration of Helsinki and was approved by the Research Committee of the Sao Paulo State University (Protocol number 97582/2016).

\section{Experimental procedures}

The participants visited the laboratory four times with at least 48 hours between each visit. On the first visit, a graded exercise test (GXT)was performed until voluntary exhaustion to measure the maximal oxygen consumption $\left(\mathrm{VO}_{2 \max }\right)$ and determine the intensity associated with $\mathrm{VO}_{2}$ max $\left(\mathrm{iVO}_{2}\right.$ max $)$. On the next three visits, supramaximal efforts were performed at $115 \%$ of $\mathrm{iVO}_{2 \max }$ to estimate $\mathrm{AC}_{\left[\mathrm{La}^{-}\right]+\mathrm{EPOCfast}}$, in such a way that the first 2 trials were applied as familiarizations to the supramaximal effort, since the typical error between MAOD and $\mathrm{AC}_{[\mathrm{La}]+\mathrm{EPOCfast}}$ was lower after 2 familiarization sessions $(0.34 \mathrm{~L})^{15}$ than after 1 familiarization $(0.67 \mathrm{~L})^{13}$.

All sessions were performed in the same period of the day to avoid any circadian influences, with controlled temperature and humidity (20.6 \pm 1.7 and $59.6 \pm 11.4 \%$, respectively). The effort procedures were performed on a motorized treadmill (ATL, Inbramed, Inbrasport, Porto Alegre, RS, Brazil) fixed at a $1 \%$ slope to reflex the outdoor running energy $\operatorname{cost}^{16}$. During the GXT and the supramaximal test, participants were verbally encouraged to perform maximally and a chest harness with the rope attached to the ceiling was used to ensure maximal effort without the risk of falling. Five minutes before all efforts, the participants performed five minutes of standard warm-up at $8 \mathrm{~km} \cdot \mathrm{h}^{-1}$ for men and $6.5 \mathrm{~km} \cdot \mathrm{h}^{-1}$ for women.

\section{Physiological Measurements}

In all procedures, gas-exchange responses were measured breath-by-breath using a stationary gas analyzer (Quark PFT, COSMED, Rome, Italy) coupled to a heart rate transmitter
(Wireless HR 138 Monitor, Cosmed, Rome, Italy). The gas analyzer was calibrated before each test following the manufacturer's instructions. Raw data obtained were smoothed every 5 points and interpolated to each second using the software OriginPro 2017 (OriginLab Corporation, Microcal, Massachusetts, USA) $)^{13,14}$.

Furthermore, to determine the blood lactate concentration([ $\left.\left.\mathrm{La}^{-}\right]\right)$, blood samples were taken from the earlobe $(25 \mu \mathrm{L})$ in the $3^{\text {rd }}$ and $5^{\text {th }}$ min after GXT and at rest, and in the $3^{\text {rd }}, 5^{\text {th }}$, and $7^{\text {th }}$ min after the supramaximal test and transferred to Eppendorf tubes containing $50 \mu \mathrm{L}$ of sodium fluoride $1 \%$. The samples were stored at $-20^{\circ} \mathrm{C}$, being posteriorly analyzed in a biochemical analyzer YSI 2900 (Yellow Spring Instruments, Ohio, USA).

\section{Graded Exercise Test (GXT)}

The GXT was designed to last 8-12 minutes, following the Howley, Bassett, $\mathrm{Welch}^{17}$ guidelines to assess the $\mathrm{VO}_{2 \text { max }}$ and $\mathrm{iVO}_{2 \max }$. Thus, the GXT started at $8 \mathrm{~km} \cdot \mathrm{h}^{-1}$ for men and $6.5 \mathrm{~km} \cdot \mathrm{h}^{-1}$ for women, with $1.5 \mathrm{~km} \cdot \mathrm{h}^{-1}$ increments every two minutes until voluntary exhaustion, respectively ${ }^{13,14}$. Voluntary exhaustion was characterized by the subject giving up or the inability to perform the effort. In addition, after the end of the GXT, the participants remained for 5 minutes in passive recovery, returning to the treadmill to run at the voluntary exhaustion workload corresponding to $105 \%$ of the peak intensity reached in the GXT to confirm the $\mathrm{VO}_{2 \max }$ value (verification test) ${ }^{18}$.

The mean of oxygen consumption $\left(\mathrm{VO}_{2}\right)$ was measured for each stage of the GXT (final 30-s of each completed stage), the highest value is considered as peak of $\mathrm{VO}_{2}$ during GXT. In addition, the peak of $\mathrm{VO}_{2}$ during the verification test was measured considering the mean of $\pm 7 \mathrm{~s}$ from the highest value of $\mathrm{VO}_{2}$ (totaling $15-\mathrm{s}$ ). The $\mathrm{VO}_{2}$ max was assumed using as the main criterion a variation of $<2.1 \mathrm{~mL} \cdot \mathrm{kg} \cdot \mathrm{min}^{-1}$ in $\mathrm{VO}_{2}$ between the final two completed stages (plateau criteria) ${ }^{17}$. When the plateau was not observed, the $\mathrm{VO}_{2 \max }$ was assumed when the difference between the peaks of $\mathrm{VO}_{2}$ measured during the GXT and verification test was $<2.1 \mathrm{~mL} \cdot \mathrm{kg} \cdot \mathrm{min}^{-118}$. In addition, the $\mathrm{iVO}_{2 \max }$ was assumed as the lowest GXT exercise intensity at which the participant reached the $\mathrm{VO}_{2 \max }{ }^{17}$. When the final stage of GXT had not been completed, the equation proposed by Kuipers, Verstappen, Keizer, Geurten, van Kranenbur ${ }^{19}$ was used.

\section{Supramaximal Effort Test and Assessement of Anaerobic Capacity}

Before the supramaximal test, the participants remained seated for $10 \mathrm{~min}$ to measure the baseline $\mathrm{VO}_{2}$. A supramaximal constant workload test at $115 \%$ was performed until voluntary exhaustion. The choice of intensity (i.e. $115 \%$ of $\mathrm{iVO}_{2 \max }$ ) was 
based on the findings of Zagatto, Bertuzzi, Miyagi, Padulo, Papoti $^{13}$ which demonstrated that $115 \%$ of $\mathrm{iVO}_{2 \max }$ is the best intensity to measure anaerobic capacity with high reliability in running. Time to exhaustion (tlim) was recorded by a chronometer. Immediately after the supramaximal test, the participants remained seated quietly for 10 minutes to measure the EPOC fast.

The e[La'] was estimated considering the net blood lactate accumulation [i.e., differences between the rest ([La-]rest) and peak ([La-]peak) values] assuming an equivalent of $3 \mathrm{~mL} \cdot \mathrm{O}_{2} \cdot \mathrm{kg}^{-1}$ per each $1 \mathrm{mmol} \cdot \mathrm{L}^{-1}$ of net lactate ${ }^{20}$. The $\mathrm{ePCr}$ was estimated considering the $\mathrm{EPOC}_{\text {fast}}$, which was calculated through the multiplication of the $\mathrm{VO}_{2}$ amplitude $\left(\mathrm{A}_{1}\right)$ and first time constant ( $\tau 1)$ (Eq. 1) obtained by bi-exponential fit (Eq. 2) using the software OriginPro 2017 (OriginLab Corporation, Microcal, Massachusetts, USA $)^{21-24}$.

$$
\text { Eq.1: } \mathrm{EPOC}_{\text {fast }}=A_{1} \times \tau_{1}
$$$$
\text { Eq. 2: } \dot{\mathrm{VO}}_{2(\mathrm{t})}=\text { baseline } \dot{\mathrm{VO}}_{2}+\mathrm{A}_{1}\left[\mathrm{e}^{-(\mathrm{t}-\delta) / \mathrm{t} 1}\right]+\mathrm{A}_{2}\left[\mathrm{e}^{-(\mathrm{t}-\delta) / t 2}\right]
$$

Where the $\mathrm{VO}_{2}(\mathrm{t})$ is the oxygen consumption at time $\mathrm{t}$, the baseline $\mathrm{VO}_{2}$ is the oxygen consumption at baseline, $\mathrm{A}$ is the amplitude, $\delta$ is the time delay, and $\tau$ is the time constant. 1 and 2 are the fast and the slow components respectively.

Thus the $\mathrm{AC}_{\left[\mathrm{La}^{-}\right]+\mathrm{EPOCfast}}$ was considered as the sum of $\mathrm{e}\left[\mathrm{La}^{-}\right]$ and $\mathrm{ePCr}^{12-14}$. In addition, the oxidative pathway was also calculated assumed as the area under the curve only during the supramaximal efforts, disregarding the baseline $\mathrm{VO}_{2} \times t \lim ^{22,24}$. Besides, all energetic pathways were relativized by the total energetic contribution (sum of oxidative and non-oxidative oxygen equivalents).

\section{Statistical Analysis}

The data normality of each variable was confirmed using the Shapiro-Wilk test to allow the use of parametric analysis. In addition, the Levene test was used to confirm the homogeneity of each variable. A Student unpaired t-test was used to compare the group differences in average values of the physiological and performance variables. The data are presented as mean \pm standard deviation (SD) and a confidence interval of 95\% (CI 95\%). In all analysis, the significant level was set at 0.05 .

Additionally, the between-group differences were analyzed by magnitude-based inference and reported as standardized mean differences ${ }^{25}$. The threshold values for Cohen's $d$ were considered as $>0.2$ (small), $>0.5$ (moderate), and $>0.8$ (large $)^{25}$. The chances of a possible substantial benefit or harm were calculated ( 0.2 multiplied by the between-subject deviation). Thus, the changes were qualitatively evaluated as follows: $<1 \%=$ most unlikely; $1 \%-5 \%=$ very unlikely; $5 \%-25 \%=$ unlikely; $25 \%-75 \%=$ possibly; $75 \%-95 \%=$ likely; $95 \%-99 \%=$ very likely; and $>99 \%=$ most likely ${ }^{26}$. When the positive and negative values were both $>5 \%$, the inference was classified as unclear. The effect size (ES) was presented as $\mathrm{ES} \pm$ confidence level (CL).

\section{Results}

The physiological responses after the GXT are shown in Table 1.

The absolute peak of $\mathrm{VO}_{2}$ reached in the GXT and verification test was greater in men compared to women, however, when expressed in relative values no differences were observed between genders. Furthermore, although none of the participants reached the $\mathrm{VO}_{2}$ plateau during GXT, no differences were observed when comparing the peak of $\mathrm{VO}_{2}$ reached in the GXT and in the verification test for male and female groups $(p=0.16$ and $p=0.80$, respectively), and thus it was considered that participants reached the $\mathrm{VO}_{2 \text { max }}$.

In addition, the $\mathrm{iVO}_{2 \max }$ was significantly higher in men, and consequently the supramaximal effort at $115 \%$ of $\mathrm{iVO}_{2 \max }$ was significantly higher in men when compared with female group $\left[16.2 \pm 1.4(\mathrm{CI} 95 \% 15.0\right.$ to 17.4$) \mathrm{km} \cdot \mathrm{h}^{-1} \mathrm{vs} 13.2 \pm 1.5$ (CI95\%: 11.9 to 14.5$\left.) \mathrm{km} \cdot \mathrm{h}^{-1}\right](p=0.001)$.

The $t$ lim measured during the supramaximal effort at $115 \%$ of $\mathrm{iVO}_{2 \max }$ for the female group $[129.4 \pm 16.5 \mathrm{~s}$ (CI95\% 115.6 to $143.1 \mathrm{~s})]$ did not present significant differences when compared with the male group $[143.0 \pm 18.1 \mathrm{~s}(\mathrm{CI} 95 \% 127.3$ to $15.7 \mathrm{~s})]$ using the null-hypothesis statistics, however, the magnitude-based inference showed a likely negative performance (Figure 1).

Table 1. GXT variables for men and women.

\begin{tabular}{|c|c|c|c|}
\hline & Men & Women & $p$ \\
\hline$\dot{\mathrm{VO}}_{2}$ VंO reached in GXT $\left(\mathrm{mL} \cdot \mathrm{kg}^{-1} \cdot \mathrm{min}^{-1}\right)$ & $42.18 \pm 3.15(39.54$ to 44.81$)$ & $41.43 \pm 2.51(39.33$ to 43.53$)$ & 0.61 \\
\hline $\mathrm{VO}_{2}$ reached in GXT $(\mathrm{L})$ & $3.02 \pm 0.47(2.63$ to 3.42$)$ & $2.43 \pm 0.31(2.16 \text { to } 2.69)^{*}$ & 0.01 \\
\hline$\dot{\mathrm{VO}} 2 \dot{\mathrm{VO}}$ reached in verification test $\left(\mathrm{mL} \cdot \mathrm{kg}^{-1} \cdot \mathrm{min}^{-1}\right)$ & $41.19 \pm 2.81(38.85$ to 43.54$)$ & $41.29 \pm 2.62(39.10$ to 43.49$)$ & 0.73 \\
\hline$\dot{\mathrm{VO}}_{2 \text { max }}$ reached in verification test $(\mathrm{L})$ & $2.95 \pm 0.47(2.56$ to 3.35$)$ & $2.42 \pm 0.32(2.15 \text { to } 2.69)^{*}$ & 0.02 \\
\hline $\mathrm{iVO}_{2 \max }\left(\mathrm{km} \cdot \mathrm{h}^{-1}\right)$ & $14.08 \pm 1.25(13.04$ to 15.12$)$ & $11.49 \pm 1.33(10.37 \text { to } 12.60)^{*}$ & 0.001 \\
\hline$\left[\mathrm{La}^{-}\right]$peak $\left(\mathrm{mmol} \cdot \mathrm{L}^{-1}\right)$ & $11.97 \pm 0.84(10.95$ to 12.98$)$ & $8.53 \pm 0.88(7.46 \text { to } 9.60)^{*}$ & 0.001 \\
\hline
\end{tabular}

Values are mean $\pm \mathrm{SD}(\mathrm{C} 195 \%)$. ${ }^{*}$ Significant differences from men $(\mathrm{p}<0.05)$. $\dot{\mathrm{VO}}_{2}=$ oxygen uptake; vt $\dot{\mathrm{VO}} 2$ maz $=$ maximal oxygen uptake verification test; $\mathrm{iVO}_{2 \max }=$ intensity associated with maximal oxygen uptake; $\mathrm{RPE}=$ Rate of perceived exertion; $[\mathrm{La}-]$ peak $=$ peak of blood lactate concentration. 

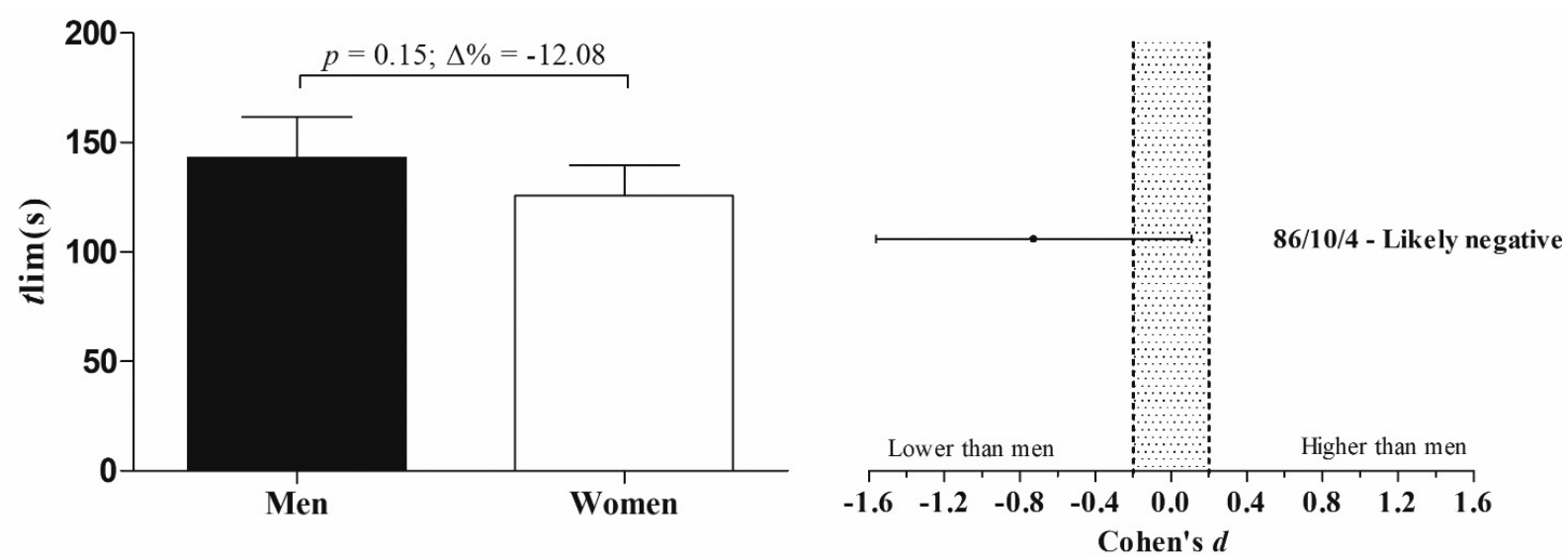

Figure 1. Time to exhaustion comparison between gender and effect size values.

The $\mathrm{AC}_{\left[\mathrm{La}^{-}\right]+\mathrm{EPOCf} \text { ast }}$ was significantly lower in women when compared with men, in absolute $(p=0.01)$ with inference most likely negative and relative values $(p=0.03)$ with inference very likely negative (Figure 2). Similarly, the $\mathrm{e}\left[\mathrm{La}^{-}\right]$in absolute and relative values and eAER in absolute values were lower in the female group compared with men $(p>0.001)$. In addition, all the participants reached a peak of lactate concentration between the third and fifth minutes after the supramaximal effort. The values of e[La $\left.{ }^{-}\right]$, ePCr, and eAER expressed in absolute and relative values are shown in Table 2.

In addition, no difference was observed $(p=0.08)$ when comparing the $\mathrm{e}\left[\mathrm{La}^{-}\right]$relativized by the total energetic contribution for women $[22.23 \pm 7.51 \%$ (CI95\% 15.95 to
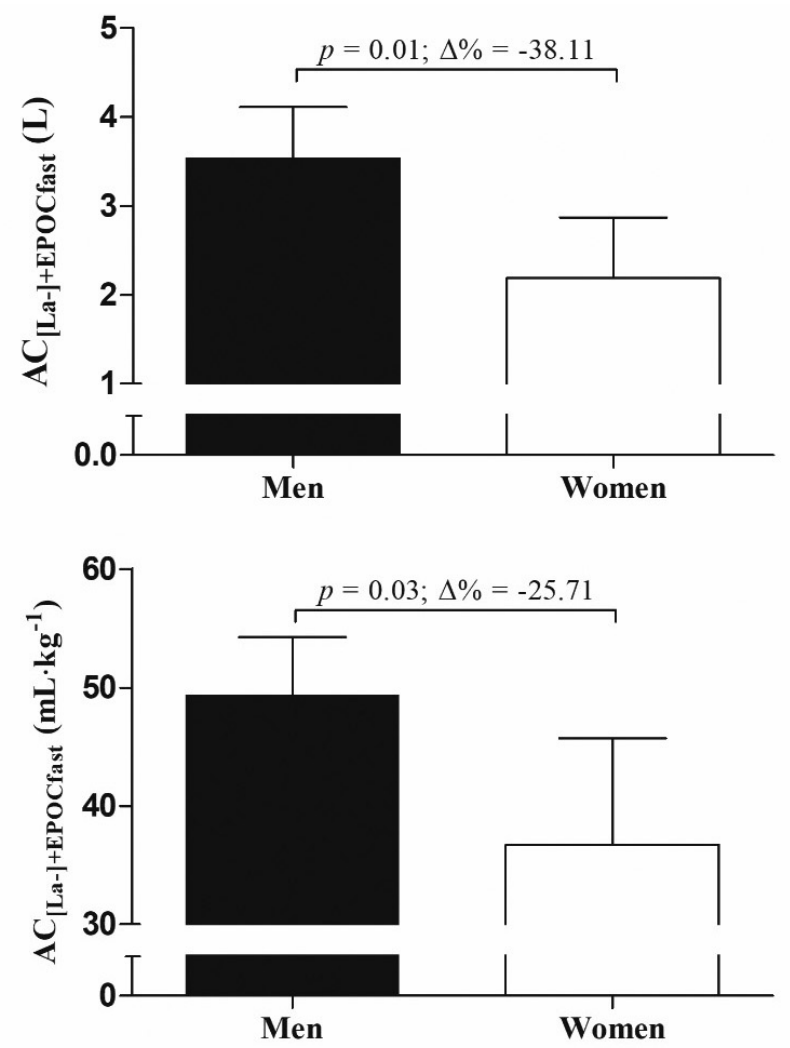

$28.51 \%$ ) when compared to men $[27.40 \pm 1.94 \%$ (CI95\% 25.77 to $29.02 \%)$ ], however an effect size $( \pm C L)$ of $-2.36 \pm 2.38$ was found, with a likely negative inference (negative: $94 \%$; trivial: $25 \%$; positive: $4 \%$ ). Moreover, no differences were observed for eAER percentage $(p=0.57)$ when comparing women $[62.75 \pm 9.43$ (CI95\%54.86 to 70.63$)]$ and men $[60.71 \pm 2.68 \%$ (CI95\% 58.47 to $62.95 \%)$, with an effect size $( \pm C L)$ of $0.68 \pm 2.14$ (unclear; negative: $65 \%$; trivial: $11 \%$; positive: $23 \%)$. Besides this, the ePCr percentage was higher $(p=0.03)$ in women $[15.02 \pm 2.56 \%$ (CI95\% 12.88 to $17.16 \%)]$ than men $[11.88 \pm 2.65 \%$ (CI95\% 9.67 to $14.10 \%)]$ with an effect size $( \pm \mathrm{CL})$ of $1.05 \pm 0.77$ and very likely positive inference (negative: $1 \%$; trivial: $3 \%$; positive: $96 \%$ ).

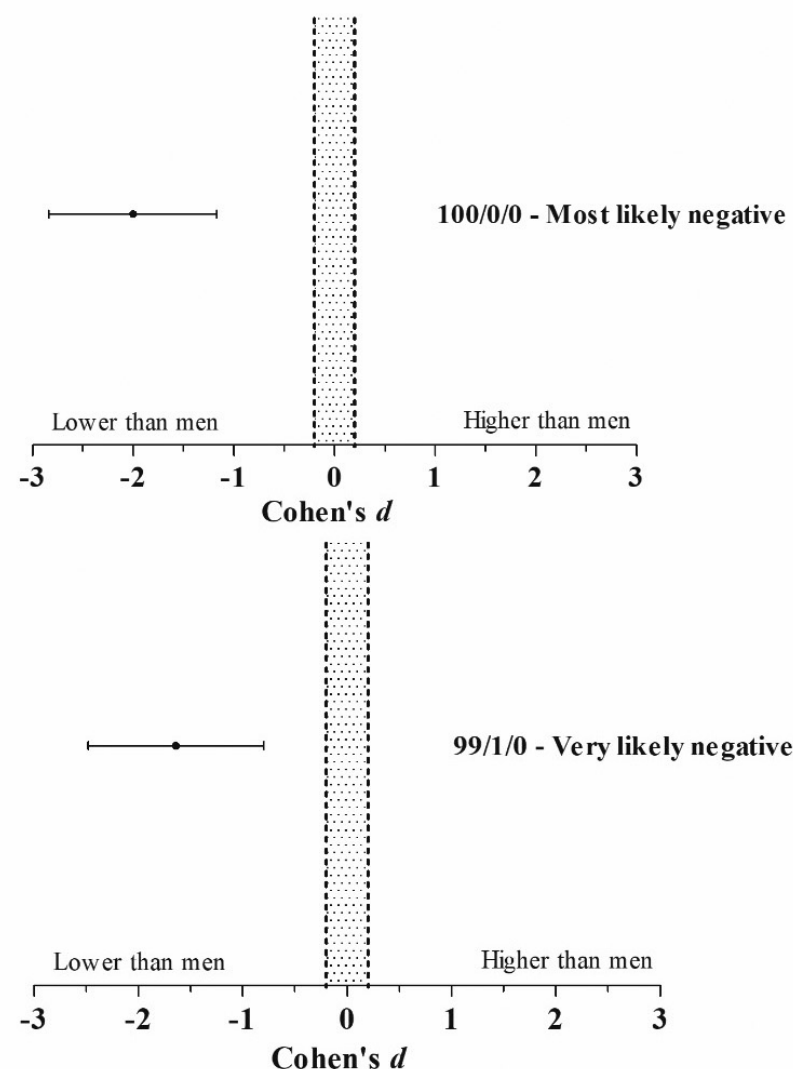

Figure 2. Comparison between gender and effect size values of anaerobic capacity measured by AC[La- $]+$ EPOCfastin relative and absolute values. 
Table 2. Energetic equivalents obtained during the supramaximal effort at $115 \%$ of $\mathrm{iVO} \mathrm{Z}_{2 \max }$

\begin{tabular}{|c|c|c|c|c|c|c|c|c|c|}
\hline & \multirow[b]{2}{*}{ Men } & \multirow[b]{2}{*}{ Women } & \multirow[b]{2}{*}{$\Delta \%$} & \multirow[b]{2}{*}{ p } & \multirow{2}{*}{$\begin{array}{c}\text { Cohen's } \\
\text { Effect Size } \\
\pm \text { CL }\end{array}$} & \multicolumn{3}{|c|}{ \%Chances } & \multirow[b]{2}{*}{ Inference } \\
\hline & & & & & & $\begin{array}{c}\text { Substantially } \\
\text { negative (-) }\end{array}$ & Trivial & $\begin{array}{c}\text { Substantially } \\
\text { positive }(+)\end{array}$ & \\
\hline $\mathrm{e}\left[\mathrm{La}^{-}\right](\mathrm{L})$ & $\begin{array}{c}2.48 \pm 0.47 \\
(2.08 \text { to } 2.87)\end{array}$ & $\begin{array}{c}1.31 \pm 0.52 \\
(0.88 \text { to } 1.75)^{*}\end{array}$ & -47.01 & 0.001 & $-2.19 \pm 0.83$ & 100 & 0 & 0 & $\begin{array}{l}\text { Most likely } \\
\text { negative }\end{array}$ \\
\hline $\mathrm{e}\left[\mathrm{La}^{-}\right]\left(\mathrm{mL} \cdot \mathrm{kg}^{-1}\right)$ & $\begin{array}{c}34.55 \pm 4.24 \\
(31.00 \text { to } 38.10)\end{array}$ & $\begin{array}{c}21.87 \pm 7.14 \\
(15.90 \text { to } 27.83)^{*}\end{array}$ & -36.71 & 0.001 & $-2.66 \pm 1.10$ & 100 & 0 & 0 & $\begin{array}{c}\text { Most likely } \\
\text { negative }\end{array}$ \\
\hline $\begin{array}{l}\text { Baseline }\left[\mathrm{La}^{-}\right] \\
\left(\mathrm{mmol} \cdot \mathrm{L}^{-1}\right)\end{array}$ & $\begin{array}{c}0.62 \pm 0.25 \\
(0.41 \text { to } 0.84)\end{array}$ & $\begin{array}{c}0.96 \pm 0.26 \\
(0.75 \text { to } 1.18)^{*}\end{array}$ & +54.68 & 0.02 & $1.20 \pm 0.79$ & 0 & 2 & 98 & $\begin{array}{l}\text { Very likely } \\
\text { positive }\end{array}$ \\
\hline $\begin{array}{l}\text { Peak [La-] } \\
\left(\mathrm{mmol} \cdot \mathrm{L}^{-1}\right)\end{array}$ & $\begin{array}{c}12.14 \pm 1.40 \\
(10.97 \text { to } 13.31)\end{array}$ & $\begin{array}{c}8.26 \pm 2.33 \\
(6.61 \text { to } 10.20)^{*}\end{array}$ & -32.00 & 0.001 & $-2.46 \pm 1.09$ & 100 & 0 & 0 & $\begin{array}{l}\text { Most likely } \\
\text { negative }\end{array}$ \\
\hline ePCr (L) & $\begin{array}{c}1.06 \pm 0.21 \\
(0.88 \text { to } 1.23)\end{array}$ & $\begin{array}{c}0.88 \pm 0.19 \\
(0.71 \text { to } 1.04)\end{array}$ & -17.28 & 0.09 & $-0.78 \pm 0.76$ & 90 & 8 & 2 & Likely negative \\
\hline $\mathrm{ePCr}\left(\mathrm{mL} \cdot \mathrm{kg}^{-1}\right)$ & $\begin{array}{c}14.87 \pm 2.87 \\
(12.47 \text { to } 17.27)\end{array}$ & $\begin{array}{c}14.85 \pm 2.51 \\
(12.75 \text { to } 16.95)\end{array}$ & -0.15 & 0.98 & $-0.01 \pm 0.75$ & 33 & 36 & 31 & Unclear \\
\hline $\mathrm{A} 1\left(\mathrm{~L} \cdot \mathrm{min}^{-1}\right)$ & $\begin{array}{c}15.26 \pm 1.91 \\
(13.66 \text { to } 16.87)\end{array}$ & $\begin{array}{c}14.90 \pm 2.47 \\
(12.84 \text { to } 16.97)\end{array}$ & -2.36 & 0.75 & $-0.17 \pm 0.91$ & 47 & 28 & 25 & Unclear \\
\hline$\tau 1(\min )$ & $\begin{array}{c}1.00 \pm 0.32 \\
(0.73 \text { to } 1.27)\end{array}$ & $\begin{array}{c}1.00 \pm 0.16 \\
(0.87 \text { to } 1.14)\end{array}$ & +0.71 & 0.96 & $0.02 \pm 0.64$ & 27 & 42 & 31 & Unclear \\
\hline eAER (L) & $\begin{array}{c}5.47 \pm 0.82 \\
(4.78 \text { to } 6.16)\end{array}$ & $\begin{array}{c}3.65 \pm 0.77 \\
(3.00 \text { to } 4.29)^{*}\end{array}$ & -33.30 & 0.001 & $-1.97 \pm 0.76$ & 100 & 0 & 0 & $\begin{array}{l}\text { Most likely } \\
\text { negative }\end{array}$ \\
\hline eAER $\left(\mathrm{mL} \cdot \mathrm{kg}^{-1}\right)$ & $\begin{array}{c}76.69 \pm 9.80 \\
\text { (68.50 to } 84.89) \\
\end{array}$ & $\begin{array}{c}63.02 \pm 15.40 \\
(50.15 \text { to } 75.89)\end{array}$ & -17.82 & 0.06 & $-1.24 \pm 1.05$ & 95 & 4 & 1 & Likely negative \\
\hline
\end{tabular}

Values are mean $\pm \mathrm{SD}(\mathrm{CI} 95 \%)$. ${ }^{*}$ Significant differences from men. $\Delta \%=$ difference in percentage from men values. e[La- $]=$ energetic equivalents of glycolytic pathway; $\mathrm{ePCr}=$ energetic equivalents of phosphagen pathway; eAER= energetic equivalents of oxidative pathway. $\left[\mathrm{La}^{-}\right]=$blood lactate concentration; $\mathrm{A} 1=$ amplitude ; $\tau 1=$ time constant.

\section{Discussion}

The present study aimed to verify if the anaerobic capacity estimated by the $\mathrm{AC}_{\left[\mathrm{La}^{-}\right]+\mathrm{EPOC} \text { ast }}$ would be modified according to gender. The main finding of the study was that women have a lower anaerobic capacity compared to men $(-25.71 \%$ in relative values and $-38.11 \%$ in absolute values), is attributed mainly to greater participation of the glycolytic pathway in men.

Despite the non-significant differences between genders in performance during the supramaximal effort $(p=0.15)$, a likely negative performance for women was observed (-12.08\%). Several studies ${ }^{7,27,28}$, have demonstrated a similar result (i.e., the non-significant difference in supramaximal time to exhaustion, with a trend of lower performance in women). This result can be explained by the oxidative pathway, as the energetic characteristic of the effort is predominantly oxidative ${ }^{29}$, and non-significant differences were observed in eAER relativized by body mass and the percentage contribution of this metabolism. Besides this, in absolute values, men present a higher value of eAER, probably because of higher muscle mass, however, this anthropometric variable was not measured.

The anaerobic capacity findings corroborate with other reports in the literature, in which men presented greater anaerobic capacity than women ${ }^{7,8}$. However, the anaerobic capacity differences between genders in the literature vary between $\sim 23 \%$ and $\sim 30 \%$ (i.e., expressed in relative values) $)^{7,8}$. These discrepancies can be attributed to differences inherent to the method for estimating anaerobic capacity. In the previously mentioned studies, the anaerobic capacity was estimated through MAOD, however, the test-retest reproducibility of this method have been questioned ${ }^{10}$. In addition, the number of submaximal exercise trials used in those studies to assess MAOD was relatively low (i.e, 2 to6), a fact that may alter the $\mathrm{VO}_{2}$-intensity linear regression to estimate the supramaximal $\mathrm{VO}_{2}$ demand and therefore to estimate the anaerobic capacity ${ }^{11}$. $\mathrm{AC}_{\left[\mathrm{La}^{-}\right]+\mathrm{EPOC} \text { Cast }}$ seems to avoid these deviations when assessed at $115 \%$ of $\mathrm{iVO}_{2 \max }$, due to the high reliability of the results (i.e., for relative values: $\mathrm{ICC}=0.77$, Typical error $=3.53 \mathrm{~mL} \cdot \mathrm{kg}^{-1}$; for Absolute values: $\mathrm{ICC}=0.87$, Typical error $=0.22 \mathrm{~L})^{13,14}$, and thus seems to present a more reliable variation in percentage.

The lower anaerobic capacity in women can be mainly attributed to the glycolytic pathway, as in the present study the $\mathrm{e}\left[\mathrm{La}^{-}\right]$was $-47.01 \%$ for absolute values and $-36.71 \%$ for relative values in women. This finding corroborates other studies where lactate accumulation was also smaller in women ${ }^{6,30,31}$. One explanation for the lower glycolytic activity is a smaller increase in plasma catecholamine during supramaximal efforts ${ }^{4,31}$, which seems to be related to differences in steroid hormone production ${ }^{32}$. A second possibility could be the differences in muscle area of type II muscle fibers which tend to be greater in men than in women ${ }^{33}$, as well as which, it is well known that type II muscle fibers are biochemically more capable of activating the glycolytic system.

The ePCr in the present study did not change between genders, despite presenting $-17.28 \%$ lower values for women, when compared with men in absolute values. Sawka, Tahamont, Fitzgerald, Miles, Knowlton ${ }^{34}$ measured the ePCr in men and women after an exhaustive run of 3 to 5 minutes 
in duration, using an equation considering the oxygen debt after the exercise ( 2 minutes). In this study the ePCr was lower in women when compared to men, even in relative values, this result is attributed to higher lean body mass in men. In addition, Esbjörnsson, Bodin, Jansson ${ }^{4}$ measured the phosphocreatine before sprints through a muscle biopsy, presenting similar values in women and men $(80 \pm 11$ and $75 \pm 18 \mathrm{mmol} \cdot \mathrm{kg}^{-1}$ dry muscle weight) with no statistical differences, thus corroborating with the results of the present study. In addition, the percentage of ePCr measured during the supramaximal effort was higher in women, this result could be assigned to a worse performance trend in women $(-12.08 \%)$, as longer periods of supramaximal exercise have great influence on $\mathrm{e}\left[\mathrm{La}^{-}\right]$and $\mathrm{eAER}^{35}$, consequently influencing the total energetic contribution and percentage of ePCr.

The main limitations of the study were the lack of relativization of energetics values by total muscle mass and active muscle mass since these results could contribute to a better understanding of the anaerobic capacity differences between genders.

\section{Conclusion}

Based on the results of the current study, it is possible to affirm that the anaerobic capacity estimated by $\mathrm{AC}_{[\mathrm{La}-]+\mathrm{EPOC} \text { fast }}$ is greater in recreationally active men compared to recreationally active women, mainly due to differences in the glycolytic pathway.

\section{References}

1. Maud PJ, Shultz BB. Gender comparisons in anaerobic power and anaerobic capacity tests. Br J Sports Med. 1986;20(2):51-54. doi:10.1136/bjsm.20.2.51.

2. Gray SR, De Vito G, Nimmo MA, Farina D, Ferguson RA. Skeletal muscle ATP turnover and muscle fiber conduction velocity are elevated at higher muscle temperatures during maximal power output development in humans. Am J Physiol Integr Comp Physiol. 2006;290(2):R376-R382. doi:10.1152/ajpregu.00291.2005.

3. Esbjörnsson M, Sylvén C, Holm I, Jansson E. Fast twitch fibres may predict anaerobic performance in both females and males. Int J Sports Med. 1993;14(05):257-263. doi:10.1055/s-2007-1021174.

4. Esbjörnsson-Liljedahl M, Bodin K, Jansson E. Smaller muscle ATP reduction in women than in men by repeated bouts of sprint exercise. J Appl Physiol. 2002;93(3):1075-1083. doi:10.1152/ japplphysiol.00732.1999.

5. Greenhaff PL, Ren JM, Soderlund K, Hultman E. Energy metabolism in single human muscle fibers during contraction without and with epinephrine infusion. Am J Physiol. 1991;260(5 Pt 1):E713-E718. doi:https://doi.org/10.1152/ajpendo.1991.260.5.E713.

6. Naughton GA, Carlson JS, Buttifant DC, Selig SE, Meldrum K, MC Kenna MJ, Snow RJ. Accumulated oxygen deficit measurements during and after high-intensity exercise in trained male and female adolescents. Eur J Appl Physiol Occup Physiol. 1997;76(6):525531. doi:10.1007/s004210050285.
7. Weber CL, Schneider DA. Increases in maximal accumulated oxygen deficit after high-intensity interval training are not gender dependent. J Appl Physiol. 2002;92(5):1795-1801. doi:10.1152/ japplphysiol.00546.2001.

8. Hill DW, Vingren JL. Effects of exercise mode and participant sex on measures of anaerobic capacity. J Sports Med Phys Fitness. 2014;54(3):255-263.

9. Weber CL, Schneider DA. Maximal accumulated oxygen deficit expressed relative to the active muscle mass for cycling in untrained male and female subjects. Eur J Appl Physiol. 2000. doi:10.1007/ s004210000214.

10. Doherty M, Smith PM, Schroder K. Reproducibility of the maximum accumulated oxygen deficit and run time to exhaustion during short-distance running. J Sports Sci. 2000;18(5):331-338. doi:10.1080/026404100402395.

11. Noordhof DA, De Koning JJ, Foster C. The maximal accumulated oxygen deficit method: A valid and reliable measure of anaerobic capacity? Sport Med. 2010;40(4):285-302. doi:10.2165/11530390-000000000-00000.

12. Bertuzzi RCM, Franchini E, Ugrinowitsch C, Kokubun E, Lima-Silva AE, Pires FO, Nakamura FY, Kiss MAPDM. Predicting MAOD using only a supramaximal exhaustive test. Int J Sports Med. 2010;31(7):477-481. doi:10.1055/s-0030-1253375.

13. Zagatto AM, Bertuzzi R, Miyagi WE, Padulo J, Papoti M. MAOD determined in a single supramaximal test: a study on the reliability and effects of supramaximal intensities. Int J Sports Med. 2016;37(9):700-707. doi:10.1055/s-0042-104413.

14. Miyagi WE, de Poli RAB, Papoti M, Bertuzzi R, Zagatto AM. Anaerobic capacityestimated in a single supramaximal test in cycling: validity and reliability Analysis. Sci Rep. 2017;7:42485. doi:http://dx.doi.org/10.1038/srep42485.

15. Zagatto AM, Redkva PE, de Poli RAB, González JAM, Brandani JZ, Penedo T, et al. 3-min all-out effort on cycle ergometer is valid to estimate the anaerobic capacity by measurement of blood lactate and excess post-exercise oxygen consumption. Eur J Sport Sci. 2019;19(5):645-652. doi:10.10 80/17461391.2018.1546338.

16. Jones AM, Doust JH. A $1 \%$ treadmill grade most accurately reflects the energetic cost of outdoor running. J Sports Sci. 1996;14(4):321-327. doi:10.1080/02640419608727717.

17. Howley ET, Bassett DR, Welch HG. Criteria for maximal oxygen uptake: review and commentary. Med Sci Sports Exerc. 1995;27(9):1292-1301. doi:10.1249/00005768-199509000-00009.

18. Rossiter HB, Kowalchuk JM, Whipp BJ. A test to establish maximum $\mathrm{O} 2$ uptake despite no plateau in the $\mathrm{O} 2$ uptake response to ramp incremental exercise. J Appl Physiol. 2006;100(3):764-770.

19. Kuipers H, Verstappen FTJ, Keizer HA, Geurten P, van Kranenburg G. Variability of aerobic performance in the laboratory and its physiologic correlates. Int J Sports Med. 1985;6(4):197201. doi:10.1055/s-2008-1025839.

20. Di Prampero PE, Ferretti G. The energetics of anaerobic muscle metabolism: A reappraisal of older and recent concepts. Respir Physiol. 1999;118(2-3):103-115. doi:10.1016/ S0034-5687(99)00083-3.

21. Margaria R, Edwards H, Dill D. The possible mechanisms of contracting and paying the oxygen debt and the role of lactic acid in muscular contraction. Am J Physiol. 1933;106(3):689-715. 
22. Brisola GMP, Miyagi WE, da Silva HS, Zagatto AM. Sodium bicarbonate supplementation improved MAOD but is not correlated with 200- and 400-m running performances: a double-blind, crossover, and placebo-controlled study. App Physiol Nutr Metab. 2015;40(9):931-937. doi:10.1139/apnm-2015-0036.

23. Milioni F, Malta E de S, Rocha LGS do A, Mesquita CAA, de Freitas EC, Zagatto AM. Acute administration of high doses of taurine does not substantially improve high-intensity running performance and the effect on maximal accumulated oxygen deficit is unclear. Appl Physiol Nutr Metab. 2016;41(5):498-503. doi:10.1139/apnm-2015-0435.

24. de Poli R de AB, Miyagi WE, Nakamura FY, Zagatto AM. Caffeine improved time to exhaustion but did not change alternative maximal accumulated oxygen deficit estimated during a single supramaximal running bout. Int J Sport Nutr Exerc Metab. 2016;26(6):549-557. doi:10.1123/ijsnem.2016-0038.

25. Cohen J. Statistical power analysis for the behavioral sciences. Stat Power Anal Behav Sci. 1988;2nd:567. doi:10.1234/12345678.

26. Hopkins WG, Marshall SW, Batterham AM, Hanin J. Progressive statistics for studies in sports medicine and exercise science. Med Sci Sports Exerc. 2009;41(1):3-13. doi:10.1249/ MSS.0b013e31818cb278.

27. Minahan C, Chia M, Inbar O. Does power indicate capacity? 30-S wingate anaerobic test vs. maximal accumulated $\mathrm{O} 2$ deficit. Int J Sports Med. 2007;28(10):836-843. doi:10.1055/s-2007-964976.

28. Ramsbottom R, Nevill ME, Nevill AM, Hazeldine R. Accumulated oxygen deficit and shuttle run performance in physically active men and women. J Sports Sci. 1997;15(2):207-214. doi:10.1080/026404197367489.

29. de Poli R de AB, Roncada LH, Malta E de S, Artioli GG, Bertuzzi R, Zagatto AM. Creatine supplementation improves phosphagen energy pathway during supramaximal effort, but does not improve anaerobic capacity or performance. Front Physiol. 2019; 10: 352. doi: 10.3389/fphys.2019.00352.

30. Itoh H, Ohkuwa T. Blood ammonia concentration after supramaximal treadmill running in males and females. J Sports Med Phys Fitness. 1993;33(3):239-245.

31. Gratas-Delamarche A, Le Cam R, Delamarche P, Monnier M, Koubi H. Lactate and catecholamine responses in male and female sprinters during a Wingate test. Eur J Appl Physiol Occup Physiol. 1994;68(4):362-366. doi:10.1007/BF00571458.
32. Zouhal H, Jacob C, Delamarche P, Gratas-Delamarche A. Catecholamines and the effects of exercise, training and gender. Sport Med. 2008;38(5):401-423. doi:10.2165/00007256-200838050-00004.

33. Gleanmark B, Hedberg G, Jansson E. Changes in muscle fibre type from adolescence to adulthood in women and men. Acta Physiol Scand. 1992;146(2):251-259. doi:10.1111/j.1748-1716.1992. tb09414.x.

34. Sawka MN, Tahamont M V., Fitzgerald PI, Miles DS, Knowlton RG. Alactic capacity and power - Reliability and interpretation. Eur J Appl Physiol Occup Physiol. 1980. doi:10.1007/BF00421318.

35. Heck H, Schulz H, Bartmus U. Diagnostics of anaerobic power and capacity. Eur J Sport Sci. 2003;3(3):1-23. doi:10.1080/17461390300073302.

\section{Acknowledgements}

RABP was supported by the São Paulo Research Foundation (FAPESP) under grant [number 2016/17836-2]. This study was financed in part by the Coordenação de Aperfeiçoamento de Pessoal de Nível Superior - Brasil (CAPES) - Finance Code 001.

\section{Corresponding author}

Alessandro Moura Zagatto.

Department of Physical Education, São Paulo State University (UNESP), School of Sciences, Bauru-SP, Brazil. Av. Eng. Luiz Edmundo Carrijo Coube, 14-01, Vargem Limpa, CEP 17033-360 Bauru, SP, Brazil.

Email: azagatto@yahoo.com.br

Manuscript received on October 18, 2018

Manuscript accepted on May 6, 2019

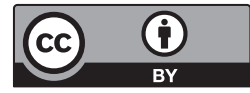

Motriz. The Journal of Physical Education. UNESP. Rio Claro, SP, Brazil - eISSN: 1980-6574 - under a license Creative Commons - Version 4.0 